\title{
Deleterious FANCL Gene Mutation
}

National Cancer Institute

\section{Source}

National Cancer Institute. Deleterious FANCL Gene Mutation. NCI Thesaurus. Code

C134510.

A change in the nucleotide sequence of the FANCL gene that is associated with increased risk of disease. 